\title{
Stress and Anger of Rural and Urban Adolescents
}

\author{
Biplob Kumar Dey1*, Abdur Rahman1, Arunavo Bairagi1, Kishor Roy² \\ ${ }^{1}$ Department of Psychology, University of Chittagong, Chittagong, Bangladesh \\ ${ }^{2}$ Department of Psychology, Jagannath University, Dhaka, Bangladesh \\ Email: ${ }^{*}$ biplob psy@cu.ac.bd
}

Received 22 December 2013; revised 23 January 2014; accepted 21 February 2014

Copyright (C) 2014 by authors and Scientific Research Publishing Inc.

This work is licensed under the Creative Commons Attribution International License (CC BY).

http://creativecommons.org/licenses/by/4.0/

(c) (i) Open Access

\begin{abstract}
The purpose of the present study was to investigate the relationship between stress and anger of rural and urban adolescents of Chittagong district in Bangladesh. The sample of the study consisted of 120 respondents of whom 60 were male ( 30 rural and 30 urban) and 60 were female (30 rural and 30 urban). Their age levels were 13 - 19. They were selected purposively from different areas of Chittagong district in Bangladesh. Bengali version of Life Stress Scale (Fahim, 2001) was used to measure life stress and Bengali version of Adolescents Anger Rating Scale (AARS) (Islam \& Chowdhury, 2011) was used to measure adolescents' anger. The obtained data were analyzed by using descriptive statistics, t-test and Pearson product moment correlation. Results revealed that the stress of urban adolescents was greater than rural; the anger of urban adolescents was more than the rural; the stress of female adolescents was more than the male and the anger of female adolescents was more than male. Results also showed that adolescents' stress was positively correlated $(r=.86, p<.01)$ with their anger.
\end{abstract}

\section{Keywords}

Adolescence; Stress; Anger

\section{Introduction}

Adolescence is the period of life from late childhood until physical growth is relatively complete and also marks the beginning of early adulthood. Age 13 through 16 is considered early adolescence and 17 through 21 is late adolescence (Wolman, 1989). The term adolescence is commonly used to describe the transitional stage of physical and psychological development between childhood and adulthood. There is no one scientific definition

${ }^{*}$ Corresponding author.

How to cite this paper: Dey, B. K., Rahman, A., Bairagi, A., \& Roy, K. (2014) Stress and Anger of Rural and Urban Adolescents. Psychology, 5, 177-184. http://dx.doi.org/10.4236/psych.2014.53028 
of adolescence or set age boundary. There is a key development change that nearly all adolescents experience during their transition from childhood to adulthood. This time frame, however, not only describes a very diverse reality, but adolescence varies considerably across cultures, over time, and within individuals (Kaplan, 2004).

Adolescence is the period of storm and stress in which adolescents suffer from more stress. Stress typically describes a negative concept that can have an impact on one's mental and physical well-being. Difficulties occur however, when stress becomes excessive. Then the person experiences disrupted emotional, cognitive and physiological functioning. Stress can be defined as feeling overwhelmed and/or unable to cope effectively with people or events in one's life. Researchers have found developmental differences in coping with stress. Older adolescents tend to use a greater array of coping strategies, especially cognitive-oriented strategies, to reduce the impact of the stressor compared to younger adolescents (Williams \& McGillicuddy-De, 1999). However, even early adolescence period, people use a variety of coping strategies, such as seeking support and using social relationships, ruminating, venting, distracting, problem-solving, as well as using humor (Broderick \& Korteland, 2002). Research findings are mixed regarding gender differences in coping during adolescence (Broderick \& Korteland, 2002; Williams \& McGillicuddy-De, 1999).

Stress is related to anger in that the more distressed a person is, the more likely she/he is to feel angry and express it or control it in some way. A person's worldview, including his or her spiritual beliefs, may also influence stress (i.e., anxiety; Beck et al., 1985) and the experience and expression of anger (i.e., anger and hostility; Beck, 1999). The gender difference seems to increase in middle to late adolescence (Compas et al., 2004). In this regard, girls appear to be more vulnerable to the negative psychological health effects of stress than boys (Charbonneau et al., 2009). Studies also provide evidences that stressful life experiences predict increase in psychological problems over time (Carter et al., 2006).

Stress is a negative state which leads to anger of an adolescent. Anger is one of the basic human emotions. It is neither "good" nor "bad," but is an emotion innate to humans (Daldrup \& Gust, 1990). Anger is an intense emotional reaction elicited by covert or overt threats such as interference, attack, aggression and frustration and characterized by an acute reaction of the autonomic nervous system (Wolman, 1989). Anger comes from various ways such as inadequacy in family life, exposure to violence at home, expectations or attitudes at home. With violent crime rising among adolescents wide spread familial abuse, continuing racial discord and recent acts of terrorism, attention has turned to anger as a major problem in human relations (Koop \& Lundberg, 1992). Adolescents are angered when their physical or social activities are prevented or in the case of an attack on their personalities, positions, or status in society. Adolescent may display anger when he or she is criticized, embarrassed, underestimated, or ignored and perceive such situations as threats to his/her extremely sensitive personality (Yazgan-Inanc et al., 2007).

According to Spielberger (1991), anger consists of two components: state anger and trait anger. State anger is a subjective emotion accompanied by muscle tension and stimulation of the autonomous nervous system; its intensity may deviate from quite mild to quite strong. The intensity of state anger may change as a function of the attack an individual perceives, or the intensity of unjustness or frustration. However, trait anger is perceived in far more situations as displeasing and frustrating, and accordingly it is described as a tendency to have rather frequent state anger. There are three dimensions of anger: physiological, social and cognitive, and behavioral and reaction. The physiological dimension of anger is related to a physiological change occurring in the body when an individual is exposed to a frustration or situation that increases anger (K1sac, 1997). The social and cognitive dimension explains the interpretation of perceived anger within an individual. The reasons for anger, fear and uneasiness are not related to the event itself, but rather to individuals' perception and how they interpret the symbols in their minds, their beliefs, comments and evaluations of the events, and the ideas produced from these beliefs, comments and evaluations (Ozer, 2000).

Adolescents who are chronically angry, prone to anger and/or have anger problems tend to experience health problems (e.g., high blood pressure and heart problems (Hauber et al., 1998); emotional distress e.g., dissociation (Calamari \& Pini, 2003); hopelessness (Kashani et al., 1995); suicidality (Goldston et al., 1996), and interpersonal difficulties; experience parents as less warm and more rejecting and controlling (Muris et al., 2004). Sexual abuse is another form of incident which is responsible for loss of social relationship of a betrayal of trust, and loss of childhood innocence. When a child experiences the disintegration of family structure through interfamilial sexual assault, he or she is more likely to experience elevated anxiety, heightened interpersonal sensitivity, increased anger problems, more paranoid ideation and increased obsessive compulsive symptoms (Murphy et al., 1988). 
From the insight of the above mentioned literature review, the present study gives rise to the research question that whether there is any effect of residential status and gender on adolescents' stress and anger.

\subsection{Rationale of the Study}

Adolescence is a very critical and transitional period of life span of a person. In that time, adolescents have to cope with their physical, social, psychological changes; that is why they have to face a lot of stressful situation such as family, school and peer group pressure which effect their life, mood and they become irritable and hopeless person. Sometimes, adolescents may fall down from their mainstream because of anger, life stress, and lack of consciousness which is threatening to their development. The findings of the study will be helpful to understand the status of stress and anger of the adolescents. The study would have some applied values and the study would give new knowledge about stress and anger of adolescence period. Therefore, this study will help us to provide such information which is very essential for mental health workers, psychologists, sociologists, governments, NGOs and policy makers to take effective steps to facilitate adolescent development.

\subsection{Objectives of the Study}

In respect of the rationale of the study, the broad objective was to find out the relation between stress and anger of rural and urban adolescents and other objectives were to find out a). the difference in stress of the adolescents according to place of residence; b). the difference in anger of the adolescents according to place of residence; c). gender variation in stress, $d$. gender variation in anger.

\section{Materials and Methods}

\subsection{Participants}

The sample of the present study consisted total 120 of whom 60 were male (30 rural and 30 urban) adolescents and 60 were female (30 rural and 30 urban) adolescents in different areas of Chittagong district. The age range of the adolescents was 13 - 19 year. The technique of sample selection was used in purposive sampling. They were selected from school in different areas of Chittagong in Bangladesh. However, all the respondents were literate adolescents who had different levels of education and were belonging to various socio-economic statuses.

\subsection{Instruments}

\subsubsection{Bengali Version of Life Stress Scale}

An adapted Bengali version of Life Stress Scale (Fahim, 2001) originally developed by (Cohen, 1999) was used to measure life stress. The questionnaire consisted of 10 items. The correlation coefficient of the Bengali version of the Life Stress Questionnaire with the English was found to be .90 at significant .01 levels. Test-retest reliabilities over a period of the two weeks were .94 , which was significant at .01 levels. This means that the reliability of the scale was satisfactory. The scoring was easy and simple. For items number 1, 2, 3, 7, 9 and 10 respondents got " 0 " for never, "1" for almost never, " 2 " for some items, "3" for fairly often, 4 for very often and for items number 4, 5, 6 and 8 respondents got " 4 " for never, " 3 " for almost never, " 2 " for sometimes, "1" for fairly often, " 0 " for very often responses. The sum was the life stress score of the respondents.

\subsubsection{Adolescents Anger Rating Scale (AARS)}

An adapted Bangla version of “Adolescent Anger Rating Scale” (AARS) (Islam and Chowdhury, 2011) originally developed by Burney (2001) used for measuring adolescents' anger. It is a self report Likert-type rating scale designed to measure specific expressions of anger of adolescents, ages 11 to 19 years. The questionnaire contains forty-one questions where twenty are instrumental anger based, eight are reactive anger based and thirteen are anger control based. The scale scores range from 41 to 164 . Higher anger scores reflect greater endorsements of anger. Twenty-eight questions are positive and thirteen are negative. There are four alternatives for each question. The alternative answers for showing anger in positive items are, a. 1 for Hardly Ever, b. 2 for Sometimes, c. 3 for Often and d. 4 for Very often. Moreover, the scoring system for negative item is just opposite of the scoring system of positive item i.e. a. 4 for Hardly Ever, b. 3 for Sometimes, c. 2 for Often and d. 1 for Very often. Reliabilities of the original version ranged from 0.81 to 0.96 . The convergent and discriminant validity of the original version are 0.57 and 0.46 respectively. The test-retest, spilt-half (odd-even) and Cronbach 
Alpha reliability of the AARS Bangla version are $0.90,0.75$ and 0.78 respectively. The Bangla version also assured high level of content and construct validity.

\subsection{Design}

A cross-sectional survey research design was followed for conducting present study.

\subsection{Procedure}

For the present study, the main purpose was to collect information about the adolescent's stress and anger. For this reason, participants were selected purposively from different areas in Chittagong district. The questionnaire was administered to each of the 120 respondents individually and at the same time rapport was established through conversation with each of them. The participants were requested to express their actual feelings and thoughts regarding to the stress and anger through each question. Those who did not understand properly, then they were given necessary explanations. Upon completion of the questionnaire, the respondents were thanked for co-operation.

\section{Results}

Data were analyzed by using t-test and Pearson product moment correlation. All statistical analyses were carried out by using the statistical program SPSS version 16.0 for windows. The results of the study are given in the following tables.

Table 1 shows that there is a significant difference between rural and urban adolescents according to stress. The mean stress score of adolescents in rural areas was 13.40 and their standard deviation was 6.39. On the other hand, the mean stress score of adolescents in urban areas was 22.45 and their standard deviation was 6.93. That means, urban adolescents showed more stress than rural adolescents.

Table 2 shows that there is a significant difference between rural and urban adolescents according to anger. The mean anger score of rural adolescents was 93.27 and their standard deviation was 22.01. On the other hand, the mean anger score of urban adolescents was 115.07 and their standard deviation was 25.19. That means, urban adolescents showed more anger than rural adolescents.

Table 3 shows that there is a significant difference between male and female adolescents according to stress. The mean stress score of male adolescents was 12.70 and their standard deviation was 5.79. On the other hand, the mean stress score of female adolescents was 23.15 and their standard deviation was 6.45 . That means, female adolescents showed more stress than male adolescents.

Table 4 shows that there is significant difference between male and female according to anger. The mean anger score of male adolescents was 86.82 and their standard deviation was 19.16. On the other hand, the mean anger score of female adolescents was 121.52 and their standard deviation was 19.53. That means, female adolescents showed more anger than male adolescents.

Table 1. Stress scores of adolescents in rural and urban areas with $t$ values.

\begin{tabular}{ccccc}
\hline Group & $\mathrm{N}$ & Mean & SD & $t$ \\
\hline Rural & 60 & 13.40 & 6.39 & 7.43 \\
Urban & 60 & 22.45 & 6.93 & \\
\hline${ }^{*} p<.05$. & & & & \\
\end{tabular}

Table 2. Anger scores of adolescents in rural and urban areas with $t$ value.

\begin{tabular}{ccccc}
\hline Group & N & Mean & SD & $t$ \\
\hline Rural & 60 & 93.27 & 22.01 & 5.05 \\
Urban & 60 & 115.07 & 25.19 & \\
${ }^{*} p<.05$. & & & & \\
\end{tabular}


Table 3. Stress score of male and female adolescents with $t$ value.

\begin{tabular}{ccccc}
\hline Group & $\mathrm{N}$ & Mean & $\mathrm{SD}$ & $t$ \\
\hline Male & 60 & 12.70 & 5.79 & 9.34 \\
Female & 60 & 23.15 & 6.45 & \\
${ }^{*} p<.05$. & & & & \\
\end{tabular}

Table 4. Anger score of male and female adolescents with $t$ value.

\begin{tabular}{ccccc}
\hline Group & $\mathrm{N}$ & Mean & SD & $t$ \\
\hline Male & 60 & 86.82 & 19.16 & \\
Female & 60 & 121.52 & 19.53 & 9.83 \\
${ }^{*} p<.05$. & & & & \\
\end{tabular}

And finally, a highly significant positive correlation $(r=.86)$ was found between stress and anger of adolescents in Chittagong district with an alpha level of $p<.01$. It reveals that the increase of stress increases the anger of adolescents.

\section{Discussion}

The present study has focused on exploring stress and anger of adolescents as a psychological phenomenon in comparison to certain socio demographic factors like gender and residential status. The first objective of the present study was that to investigate whether there are any differences between rural and urban adolescents according to stress. Urban adolescents suffer more stress than rural adolescents. Urban parents have high expectation to their children to get good grades. To fulfill their expectations, adolescents always remain in pressure and stress. Therefore, the peer pressure, the competitive environment in the schools, busy work schedule of parents, demand of teachers for good grades create more stressful situation to the urban adolescents than rural. In urban adolescents, girl experienced significantly more academic stress than the boy. And the experience of academic stress leads to a sense of distress and anger, which is generally manifested in a variety of psychological and behavioral problems. Sometimes, academic pressure as an acute stress factor that leads to mental distress, anger and in extreme cases, to suicide (Lee \& Larson, 1996; Schoolland, 1990). The results were similar to the results of Vijaylakshmi \& Lavanya (2006) which revealed that urban students experienced more stress as compared to rural students. These findings were supported the findings of the present study relating to urban and rural differences in stress.

The second objective of the present study was to observe whether there is any difference between rural and urban adolescents according to anger. The findings of the present study were that urban adolescents show more anger than rural. Life in inner city is characteristic by numerous factors such as violence, physical aggression, poor housing, drug using that can affect the safety, psychological development of the adolescents that are exposed to those factor on a daily basis. Additional knowledge and understanding of the influence of day-to-day stressors or daily hassles can enhance the assessment of the contributing factors of psychosocial distress among urban adolescents. And these factors (violence, physical aggression, poor housing, drug using) are common among people of low socio-economic status and which create anger among urban adolescents. Therefore, emotional rejection, lack of involvement by the object of loss; or physical absence, including separation, and divorce are common among in urban people (especially people of low socio-economic status) and children in urban areas often respond to these absences by withdrawing, becoming hopeless, feeling depressed, and/or getting angry (Garmezy, 1986). These findings are supported the findings of the present study relating to urban and rural differences in anger.

The third objective of the present study was that to see whether there is any difference between male and female adolescents according to stress. And the finding was that female adolescents would suffer more stress than male adolescents. Female and male adolescents have seemingly different experienced when coping with stress. 
Interpersonal stress seems to be more acute for girls whether it is from coping with daily stressors at home and at school. All-girl schools have an effect on girls' sense of belonging, thereby reducing their stress levels. Boys experience less stress than girls do regarding their bodily self-esteem, self-image and health. Girls remain more stress than boys in adolescence period. Society expects different behaviour from boys and girls. The girls are supposed to be submissive, well mannered, docile, while the boys are supposed to be aggressive and independent. For this reason, girls do not express their emotion and it leads to the emotional problem including stress, anger, depression and anxiety. In adolescence, girls and boys remain in romantic and emotional mood. Sometimes, they engage in romantic relation. But the girls suffer more stress than boys in respect of maintaining relationship. Sometimes this relationship may cause unexpected pregnancy (Roberts et al., 2005). These findings were supported the findings of the present study relating to gender differences in stress.

The fourth objective of the present study was that to watch whether there is any difference between male and female adolescents according to anger. And the finding was that female adolescents would show more anger than male. Now in Bangladesh, girls are actively taking part in all sectors of education like boys. In this competition with their counterpart, the girls face many problems. It is, therefore, plausible that the girls express protest behavior against unequal treatment and injustice through anger and aggression. This finding about greater anger in girls than boys has been supported by some research findings conducted in recent years. Thus, Lanctot \& LeBlanc (2003) conducted the Gender and Anger Project in Canadian Institutes for Health Research and reported that gender difference in anger has several forms. It was concluded that females tend to engage more in relational aggression and anger, but males tend to engage more in physical aggression and anger (Crick, 1995). These findings were supported the findings of the present study relating to gender differences in anger.

And finally, the main objective of the present study was to find out relation between anger and stress of adolescents in rural and urban areas in Chittagong district. The finding of the present study was that positive correlation was found between stress and anger of adolescents in rural and urban areas. The results revel that if the stress is high than the anger of those adolescents will be high. Adolescents face many stress which comes from puberty, changing relationships with peers, new demands of school, safety issues on their neighborhoods, romantic relationships and responsibilities to their families. The way in which they cope with this stress can have significant short and long-term consequences on their physical and emotional health. Difficulties in handling stress may engage in behaviors such as fighting or inappropriate risk-taking, negativism, and displaced anger (Adler, 1956; Corsini \& Manatees, 1982).

\section{Limitations}

In this study, the sample was drawn purposively as well as sample size was small. As a result, this sample is not enough to represent the true status. That is why the findings cannot be over generalized to all of adolescents of Bangladesh. In this sense, in order to increase generalization of the study further higher order analysis could be performed. Further research is needed to explore of other variables with stress and anger of adolescents on the basis of types of gender and residential status.

\section{Conclusion}

In sum, the current research adds to the psychology literature, because it explored causes of stress and anger, adolescents' coping with stress and anger, effects of stress and anger of adolescents in a Bangladeshi sample. So, necessary initiative should be taken to reduce the adolescents' stress and anger through some services like counseling, psychotherapy, family therapy, group therapy, social skill training and motivational intervention. Cognitive behavioural group treatment plan will be effective for adolescents by reducing stress and anger. Counseling programme should be provided to enhance the self-esteem of the adolescents that will help them to reduce stressful and depressive symptoms. Parents have to understand their sons' or girls' demand and expectation. They should be conscious that learning may not be burden to their sons or girls. They also should be more careful about choosing peer group. They should maintain strong emotional bond with their sons or girls. The school authority should provide their learning programs based on adolescents' maturity level. And the social context of Bangladesh needs to be improved so that girls can move freely. This study may have important implications for psychologists, social workers, organizations working with stressful and angry adolescents. The findings from these types of research will definitely help us to understand the reason, causes and consequences of stress and anger of adolescents in Bangladesh and thus will contribute to reducing the stress and anger of 
them. Finally, it is worthwhile to suggest further in depth research with large and representative sample in this area so as to find out more variables revealing significant relation between stress and anger of adolescents in the social context of Bangladesh.

\section{References}

Adler, A. (1956). Understanding Life. In H. L. Ansbacher, \& R. R. Ansbacher (Eds.), The Individual Psychology of Alfred Adler: A Systematic Presentation in Selections from His Writings. New York, NY: Harper Torch Books.

Beck, A. (1999). Prisoners of Hate: The Cognitive Basis of Anger Hostility and Violence (pp. 223-278). New York: Harper Collins.

Beck, A., Emery, G., \& Greenberg, R. (1985). Anxiety Disorders and Phobias. A Cognitive Perspective (pp. 300-368). New York: Basic Books.

Broderick, P. C., \& Korteland, C. (2002). Coping Style and Depression in Early Adolescence: Relationships to Gender, Gender Role, and Implicit Beliefs. Sex Roles, 46, 201-213. http://dx.doi.org/10.1023/A:1019946714220

Burney, D. M. (2001). Initial Development and Score Validation of the Adolescent Anger Rating Scale. Educational and Psychological Measurement, 61, 446-460. http://dx.doi.org/10.1177/00131640121971310

Carter, J. S., Garber, J., Ciesla, J. A., \& Cole, D. A. (2006). Modeling Relations between Hassles and Internalizing and Externalizing Symptoms in Adolescents: A Four Year Prospective Study. Journal of Abnormal Psychology, 115, 428-442. http://dx.doi.org/10.1037/0021-843X.115.3.428

Charbonneau, A. M., Mezulis, A. H., \& Hyde, J. S. (2009). Stress and Emotional Reactivity as Explanations for Gender Differences in Adolescents’ Depressive Symptoms. Journal of Youth and Adolescence, 38, 1050-1058. http://dx.doi.org/10.1007/s10964-009-9398-8

Cohen, J. (1999). Statistical Power Analysis for the Behavioral Sciences (2nd ed.). Hillsdale, NJ: Lawrence Erlbaum Associates.

Compas, B. E., Connor-Smith, J., \& Jaser, S. S. (2004). Temperament, Stress Reactivity and Coping: Implications for Depression in Childhood and Adolescence. Journal of Clinical Child and Adolescent Psychology, 33, 21-31. http://dx.doi.org/10.1207/S15374424JCCP3301_3

Corsini, R. J., \& Manatees, G. J. (1982). Individual Psychology. Itasca, NY: Peacock Publishers, 6, 130-180.

Crick, N. R. (1995). A Review and Reformulation of Social Information-Processing Mechanisms in Children's Social Adjustment. Psychological Bulletin, 115, 74-101. http://dx.doi.org/10.1037/0033-2909.115.1.74

Daldrup, R. J., \& Gust, D. (1990). Freedom from Anger (pp. 344-365). New York, NY: Simon \& Schuster.

Fahim, Y. (2001). How Stressful of Your Life Stress. The Dhaka University Journal of Psychology, 25, 24-27.

Garmezy, N. (1986). Developmental Aspects of Children's Responses to the Stress of Separation and Loss. In M. Rutter, C. E. Izard, \& P. B. Read (Eds.), Depression in Young People (pp. 70-89). New York: Guilford Press.

Goldston, D., Daniel, S., Reboussin, D., Kelly, A., Levers, C., \& Brunstetter, R. (1996). First-Time Suicide Attempters, Repeat Attempters, and Previous Attempters on an Adolescent in Patient Psychiatry Unit. Journal of the American Academy of Child and Adolescent Psychiatry, 35, 631-639. http://dx.doi.org/10.1097/00004583-199605000-00018

Hauber, R., Rice, M., Howelli, C., \& Carmon, M. (1998). Anger and Blood Pressur. (pp. 139-178) Harvard University Press. From Ephost Database.

Islam, S., \& Chowdhury, L. (2011). Adaptation of Adolescents Anger Rating Scale According to Age and Sex. The Dhaka University Journal of Psychology, 30, 35-38.

Kaplan, P. S. (2004). Adolescence (pp.1, 4, 81). Boston: Houghton Mifflin Company.

Kashani, J., Dahlmeier, J., Borduin, C., Solitys, S., \& Reid, J. (1995). Characteristics of Anger Expression in Depressed Children. Journal of the American Academy of Child and Adolescent Psychiatry, 34, 322-326.

http://dx.doi.org/10.1097/00004583-199503000-00017

Kisac, I. (1997). Trait Anger and Anger Expression Levels of University Students According to Some Variables. Unpublished Doctoral Dissertation, Ankara: Hacettepe University.

Koop, C. E., \& Lundberg, G. D. (1992). Violence in America: A Public Health Emergency. Journal of the American Medical Association, 267, 3075-3076. http://dx.doi.org/10.1001/jama.1992.03480220093036

Lanctot, N., \& Leblanc, M. (2003). The Structure and Growth of Violence. Interdisciplinary Conference (pp. 7-12). Edinburgh.

Lee, M., \& Larson, R. W. (1996). Effectiveness of Coping in Adolescence: The Case of Korean Examination Stress. International Journal of Behavioral Development, 19, 851-869. 
Muris, P., Meesters, C., Morren, M., \& Moorman, L. (2004). Anger and Hostility in Adolescents: Relationships with SelfReported Attachment Style and Perceived Parental Rearing Styles. Journal of Psychosomatic Research, 57, $257-264$. http://dx.doi.org/10.1016/S0022-3999(03)00616-0

Murphy, S. M., Kilpatrick, D. G., Amick-Mcmullan, A., \& Verson, L. J. (1988). Current Psychological Functioning of Child Sexual Assault Survivors: A Community Study. Journal of Interpersonal Violence, 3, 55-79. http://dx.doi.org/10.1177/088626088003001005

Ozer, A. K. (2000). Being Addicted to Self-Esteem: Being Able to Cope with Emotional Tension. (pp.67-87). Istanbul: Sistem Publishing.

Roberts, T. A., Auinger, P., \& Klein, J. D. (2005). Intimate Partner Abuse and the Reproductive Health of Sexually Active Female Adolescents. Journal of Adolescent Health, 36, 380-385. http://dx.doi.org/10.1016/j.jadohealth.2004.06.005

Schoolland, K. (1990). Shogun's Ghost: The Dark Side of Japanese Education (pp. 28-32). New York: Bergin \& Garvey.

Spielberger, C. D. (1991). State-Trait Anger Expression Inventory (pp. 67-80). Orlando, FL: Psychological Assessment Resources.

Vijaylakshmi, G., \& Lavanya, P. (2006). Relationship between Stress and Mathematic Achievement among Intermediate Students. Education tracks, 7, 34-37.

Williams, K., \& Mcgillicuddy-De L, A. (1999). Coping Strategies in Adolescents. (Electronic version). Journal of Applied Developmental Psychology, 20, 537-549. http://dx.doi.org/10.1016/S0193-3973(99)00025-8

Wolman, B. B. (1989). Dictionary of Behavioral Science. (pp. 234-246). San Diego, CA: Academic Press.

Yazgan-Inanc, B., Bilgin, M., \& Atici, M. (2007). Development Psychology, Child and Adolescent Development (pp. 76-98). Ankara: Pegem A Publishing. 